\title{
El reposicionamiento de las ciudades y regiones urbanas en una economía global: ampliando las opciones de políticas y gobernanza**
}

\begin{abstract}
This paper addresses two critical urban and regional policy issues. One concerns actual shifts in the scales, spaces and contents of economic activity, focusing in three types of critical processes: The ongoing formation of global cities; the novel trend towards the formation of mega-regions and the expansion of cross-border flows connecting cities at diverse levels of the urban hierarchy The second concerns the needed shifts in our interpretations and policy frameworks to adjust to these novel trends and maximize their benefits and distributive potential, examining some of the key challenges these developments generate for globalising cities and urban areas, from economic to social.
\end{abstract}

Key words: global cities, mega regions, governance

\section{Resumen}

Este artículo da cuenta de dos temas críticos de políticas urbanas y regionales. El primero se refiere a los cambios recientes en las escalas, espacios y contenidos de la actividad económica, concentrándose en tres tipos de procesos críticos: la actual formación de las ciudades globales; la nueva tendencia hacia la formación de mega-regiones y, finalmente, la expansión de flujos trans-fronterizos que conectan a las ciudades a diversos niveles de la jerarquía urbana. El segundo se refiere a los cambios en las interpretaciones y esquemas de políticas requeridos para ajustarse a estas nuevas tendencias y maximizar sus beneficios y potencial distributivo, donde se examinarán algunos de los desafíos claves que generan estos desarrollos para las ciudades y áreas urbanas en proceso de globalización, desde lo económico a lo social.

Palabras clave: ciudades globales, mega-regiones, gobernanza 


\section{Introducción}

L os procesos de globalización están teniendo diversos impactos en las principales áreas urbanas y, como resultado, las políticas urbanas tendrán que ir más allá de la preocupación familiar por los "problemas urbanos" de manera de ayudar a las ciudades a beneficiarse y abordar las implicancias de la globalización. En este artículo se proponen dos vías promisorias para ampliar el terreno de las políticas urbanas. Por una parte, construir una dimensión urbana más fuerte al interior de políticas que no siendo específicamente urbanas, tienen agudos impactos urbanos; el punto crítico es la falta de dimensión espacial de estas políticas. Por otra parte, entender qué tipos de acción inter-gubernamental conjunta se necesitan en la medida que la política urbana en ciudades en proceso de globalización no puede ser limitada a gobiernos nacionales o regionales/locales.

El artículo aborda estos temas críticos de políticas examinando dos conjuntos de procesos principales. Uno se refiere a los actuales giros en las escalas, espacios y contenidos de la actividad económica. El segundo se refiere al giro necesario en nuestras interpretaciones y esquemas de políticas para ajustarse a estas nuevas tendencias y maximizar sus beneficios y su potencial distributivo.

Primero, examinaré algunos de los componentes clave de los "procesos de globalización" y su significado para diferentes tipos de ciudades y regiones urbanas. Más que revisar todos los componentes, destacaré tres tipos de procesos críticos. La formación en curso de ciudades globales es uno de ellos, pero como esto es una tendencia bien documentada, sólo la abordaré cuando se vincule con otros dos desarrollos que son examinados con mayor detalle. Uno es la nueva tendencia hacia la formación de mega-regiones, que en el caso de algunas regiones, como Europa, tiende a ser un proceso trans-fronterizo. El otro es la expansión de flujos trans-fronterizos que conectan ciudades a diversos niveles de la jerarquía urbana. Para capturar el crecimiento y diversificación de estos flujos interciudades, desarrollaré un tipo de muestra de un

* Columbia University y London School of Economics. E-mail: sjs2@columbia.edu.

** Traducido por Luis Riffo Perez. E-mail: 1riffop@uc.cl "mundo pequeño" de varias ciudades diversas, desde aquellas globalmente poderosas a las más débiles, y definiré sus interconexiones; el propósito es ampliar el conjunto de ciudades en proceso de globalización en el análisis, más allá de las cuarenta ciudades globales usuales principales $y$, reducir analíticamente el peso abrumador de estas ciudades.

Estas formaciones - mega-regiones y geografías inter-ciudades-son muy diferentes. Argumentaré que es posible, analíticamente, identificar una dinámica distinta en curso en estos dos muy diversos componentes: ciudades en proceso de globalización y regiones urbanas. Esta dinámica es la interacción entre la dispersión geográfica y nuevos tipos de economías de aglomeración. La especificación de un marco analítico común para estas dos muy diversas formas espaciales debería permitirnos desarrollar una aproximación más aguda sobre las políticas y, en segundo lugar, establecer el poder de negociación actual de los actores urbano/regionales, así como nuevos tipos de actores inter-gubernamentales. Estas dos formas espaciales también deberían ayudar en la evaluación del grado en el cual las decisiones de políticas pueden fomentar una mayor integración económica entre la ciudad (o ciudades) más globalizada de un país y sus otras áreas metropolitanas que actualmente desempeñan funciones subordinadas dentro de la jerarquía urbana nacional. En otras palabras, el tomar una escala mega-regional puede ayudar a conectar a los "ganadores" y los "rezagados" -la mega región se convierte en una escala que incluye ciudades y áreas tanto globalizadas como locales y provinciales-. Pero esta conexión de ganadores y rezagados también puede ser extendida a redes inter-ciudades trans-fronterizas mediante el fortalecimiento de las conexiones de ganadores y rezagados entre fronteras.

Una consecuencia es que no solo los ganadores son privilegiados, como se ha vuelto común con la focalización de recursos orientados a permitir la formación de ciudades de clase mundial, sino que también las rezagadas, en la medida que ellas están dinámicamente interconectadas dentro de un área ganadora y/o dentro de una red transfronteriza. Puede significar que más que perseguir sólo políticas económicas focalizadas en los sectores más avanzados también resulta relevante 
orientar recursos hacia las regiones más pobres, pero no como caridad sino que reconociendo que ellas son parte de nuevas dinámicas económicas que combinan la necesidad de áreas dispersas de bajos costos y áreas densas de altos costos. Para mencionar sólo uno de muchos ejemplos, este tipo de esquema podría traer valor a áreas más pobres dentro de los países más desarrollados, las cuales podrían ser desarrolladas para convertirlas en ventajosas para la localización de actividades que por ahora son transferidas a países de bajos salarios. El objetivo sería evitar una carrera hacia abajo y proveer rutas de desarrollo alternativas a la de privilegiar actividades de punta, tales como parques biotécnicos, parques de oficinas de lujo, como ocurre hoy en los países desarrollados.

Segundo, el artículo examinará algunos de los desafíos clave que generan estos desarrollos para las ciudades y áreas urbanas en proceso de globalización, desde lo económico a lo social. Una cuestión crítica aquí es ¿que pasará si se permite que continúen las actuales políticas y trayectorias de desarrollo? Para abordar esta cuestión el artículo usa el caso de la "economía del conocimiento" como ventana dentro de un conjunto de temas que están confrontando las ciudades y regiones. ¿Cuál es el rol de las ciudades en la competitividad regional y cuánto pueden ser más efectivamente unidas las actuales políticas territoriales y urbanas? Esta orientación también puede añadir a nuestra comprensión de instrumentos "blandos" de políticas - por ejemplo en la educación superior, destrezas, innovación, áreas de política empresariales y sociales- que pueden ser reconfigurados en orden a enfrentar estos retos de manera más efectiva, y obtener un sentido de qué es lo que debe cambiar y por qué. Por ejemplo, aun el sector más avanzado requiere un conjunto de empleos (camioneros, aseadores, etc.) y sectores económicos ("manufacturas urbanas") y ciertos componentes de los nuevos tipos de economía informal) que usualmente no reconocemos como pertenecientes a la economía avanzada. Identificar estos tipos de articulaciones ayudaría a identificar cómo ciertas políticas sectoriales específicas deberían operar en conjunto, lo cual no ocurre en muchos casos; necesitamos reconocer que un sector de servicios avanzados fuerte puede necesitar un sector industrial urbano que funcione bien. Otro tipo de articulación que debe ser reconocido es que ciertas políticas no urbanas en realidad pueden tener efectos fuertes sobre ciudades y regiones.

\section{Elementos centrales en las ciudades y regiones urbanas de hoy}

Introduciré las principales líneas de análisis desarrolladas en este artículo. En primer término daré cuenta brevemente de las dos nuevas formaciones espaciales ya referidas y sus implicaciones para la política y la realidad socio-económica de ciudades y regiones urbanas. En seguida, me referiré brevemente a la economía del conocimiento y las políticas blandas que ella engendra. Estas dos breves secciones son un resumen de la primera y segunda mitad respectivamente de este artículo.

\section{Nuevas formaciones espaciales}

\section{Mega-regiones}

Una tendencia principal evidente en todo el mundo es la formación de escalas urbanas crecientemente grandes, las cuales en cierto momento pueden ser descritas como mega-regiones. A menudo, ellas son simplemente vistas como más de lo mismo -más personas, más paisajes urbanos interminables-. En su aspecto más elemental, la mega-región resulta del crecimiento de la población en un contexto geográfico donde ciudades y áreas metropolitanas se mezclan entre sí. Y esto, en efecto, conduce a infraestructuras interregionales, notablemente transporte y electricidad, y varias formas de planificación y coordinación regional, como puede ser observado hoy. Pero, ¿son estas condiciones, que implican una versión expandida de las economías de urbanización, todo lo que hay que considerar?

La mega-región emerge como un territorio suficientemente diverso en su interior, por lo que deberían ser exploradas nuevas estrategias de desarrollo para generar ventajas tanto en las áreas más avanzadas como en las menos avanzadas dentro de la mega-región. Ellas deberían considerar marcos amplios e innovadores de gobernanza. Las ventajas familiares de escalas mayores a la ciudad, tales como las escalas metropolitanas y regionales, provienen de compartir infraestructuras de transporte para personas y bienes, lo cual fortalece mercados de vivienda robustos, $y$, posiblemente, 
apoya el desarrollo de parques científicos, tecnológicos y de oficinas. Más complejo y elusivo es el problema de si los beneficios de la interacción económica mega-regional pueden ir más allá de estas tradicionales economías de escala. No existe una investigación definitiva sobre este tema. De esta forma, la especificación empírica puede ser sólo parcial ya que la evidencia disponible para el nivel urbano es fragmentada, un defecto que se vuelve agudo al tratar con la nueva categoría de mega-región. Existe sin embargo, suficiente análisis y evidencia sobre un componente particular de este tema -las ventajas para las firmas globales y mercados de formas particulares de economías de aglomeración al nivel urbano- que podemos empezar a usar como lentes sobre la escala megaregional. Las economías de aglomeración deben ser distinguidas de las familiares economías de urbanización. Ellas implican interacciones complejas de diversos componentes, no simplemente, por ejemplo, más personas usando una línea de metro y las economías de escala que esto permite.

Las ventajas específicas de la escala mega-regional consisten en, y emergen de, la coexistencia dentro de un espacio regional de múltiples tipos de economías de aglomeración. Estos tipos de economías de aglomeración están hoy distribuidos a lo largo de diversos espacios económicos y escalas geográficas: distritos centrales de negocios, parques de oficinas, parques científicos, las eficiencias en transporte y vivienda derivadas de grandes (pero no demasiado grandes) cinturones de conmutación, distritos de manufacturas de bajo costo (hoy a menudo en el exterior) destinos turísticos, ramas especializadas de la agricultura, tales como la horticultura o la comida cultivada orgánicamente, y los complejos evidentes en las ciudades globales. Cada uno de estos espacios muestra distintas economías de aglomeración y, a lo menos empíricamente, se fundan en tipos diversos de contextos geográficos, desde lo urbano a lo rural, de lo local a lo global.

La tesis es que una mega-región es suficientemente grande y diversa de manera que acomoda un rango bastante más amplio de tipos de economías de aglomeración y contextos geográficos que los que actualmente existen. Esto llevaría las ventajas de localización mega-regional más allá de la noción de economías de urbanización. Una mega-región puede ser vista entonces como una escala que puede beneficiarse del hecho de que nuestras complejas economías necesitan tipos diversos de economías de aglomeración y contextos geográficos, desde economías de aglomeración extremadamente altas, como lo muestran los servicios corporativos avanzados especializados, a las bastante modestas economías mostradas por los parques de oficinas suburbanos y las manufacturas regionales trabajo-intensivas de bajos salarios. Puede incorporar esta diversidad dentro de una única mega-zona económica. De hecho, en principio, podría crear condiciones para el regreso de actividades particulares (no todas) ahora transferidas a otras regiones o localizaciones extranjeras ${ }^{1}$.

Así, la dimensión crítica para los propósitos de este artículo no es sólo una cuestión de los contenidos de una mega-región, tales como sus sectores económicos, infraestructura de transporte, mercados de vivienda, tipos de bienes y servicios que son producidos y distribuidos, exportados e importados - una suerte de rayos $\mathrm{x}$ de la megaregión-. También crítica es la especificación de las interacciones económicas dentro de la megaregión, en orden a detectar qué podría ser re-incorporado en la región (por ejemplo, fábricas o trabajos rutinarios de escritorio que están siendo transferidos a otras áreas nacionales o extranjeras), así como a detectar ventajas mega-regionales emergentes.

\section{Redes económicas trans-fronterizas}

Para llegar a la pregunta sobre ciudades y la economía global, es útil especificar los múltiples circuitos globales a través de los cuales las ciudades se están conectando entre las fronteras. Redes particulares conectan grupos particulares de ciudades. Esto nos permite recuperar detalles sobre los diversos roles de las ciudades en la economía global. La formación de geografías inter-ciudades está contribuyendo a las infraestructuras sociotécnicas para una nueva economía política global,

Aparte de "regionalizar" varios segmentos de una cadena de operaciones de una firma, uno podría también proponer regionalizar más segmentos de varias cadenas de mercancías. Ver, por ejemplo, Gereffi, Humphrey y Sturgeon (2005). 
nuevos espacios culturales, y nuevos tipos de redes sociales. Algunas de estas geografías inter-ciudades son densas y altamente visibles -los flujos de profesionales, turistas, artistas, y migrantes entre grupos específicos de ciudades-. Otras son delgadas y escasamente visibles -las altamente especializadas redes de transacciones financieras electrónicas que conectan a ciudades particulares dependiendo del tipo de instrumento involucrado-. Un poco más densas son las cadenas de mercancías globales para diversos productos que van desde centros exportadores a centros importadores.

En el artículo examinaré las redes inter-ciudades top generadas por las 100 firmas principales en el sector de servicios corporativos especializados, específicamente legales, publicidad, consultorías de gestión, contabilidad y seguros. La base de datos de Taylor fue usada para seleccionar a 24 de 100 ciudades, las que abarcan un conjunto de localizaciones en el mundo y en la jerarquía urbana global (ver Tabla 1 para detalles). El esfuerzo fue entender las geografías inter-ciudades entre grupos de ciudades seleccionadas de forma aleatoria, de manera de capturar un "mundo pequeño" que posiblemente revele interconexiones inesperadas y a menudo difícilmente visibles o conocidas. Analizar las jerarquías globales y las redes dominadas por los centros económicos más poderosos nos permite descubrir tales geografías inter-ciudades.

Estas firmas globales producen y entregan insumos críticos para firmas y mercados, y aun gobiernos, alrededor del mundo. Ellas sirven al tipo de firmas involucradas en el comercio de commodities y mercados futuros, y a las firmas de servicios financieros que se describen más adelante. Además sirven a firmas de arquitectura e ingeniería, a las principales exhibiciones de arte y bienales y circuitos de avanzada. En síntesis, ellas están en el negocio de servicios especializados y listas para entregar innovaciones de punta no sólo para las firmas sino para otros tipos de organizaciones.

\section{La economía del conocimiento y el lugar}

La profunda historia económica de un lugar es actualmente una variable crítica en el desarrollo de una economía del conocimiento competitiva. Si esto es así, entonces una de las cosas que importan en una economía global es la diferencia específica de una ciudad o región. Esto posiciona a las ciudades y regiones urbanas en términos de sus diferencias específicas más que de la noción común de ver a las ciudades en competencia directa con todo tipo de ciudades que se están convirtiendo todas en similares. El argumento va en contra de dos nociones muy comunes: i) que "la" economía del conocimiento es algún tipo de entidad estandarizada, sin importar cuán estado-del-arte sea; en este enfoque, las políticas se orientan a capturar algo de esa economía del conocimiento que pareciera flotar sobre todo y traerla hacia un área; y ii) para que la economía del conocimiento se arraigue en un área y se desarrolle, el área debe superar/sobrepasar/destruir sus viejas economías materiales (industria manufacturera, minería, agricultura, etc.). Mi investigación sugiere que las economías del conocimiento más fuertes tienen imbricaciones complejas con la historia profunda de un lugar (ciudad, región) incluyendo sus antiguas economías materiales.

Mi segundo argumento es que la economía del conocimiento depende realmente de grandes infraestructuras sociales y económicas y de antiguas economías materiales que han sido mayoritariamente mantenidas invisibles y que han sido devaluadas. Las economías del conocimiento son fácilmente reducidas a sus componentes de "conocimientos". Pero ellas a) requieren componentes distintos a los de la economía del conocimiento: por ejemplo, la producción de un instrumento financiero requiere no sólo de conocimiento y software, sino que de un conjunto de condiciones materiales, incluyendo camiones que traigan el software y b) las economías del conocimiento están a menudo "incrustadas" en sectores distintos a ellas. Por ejemplo, el componente economía del conocimiento puede estar incrustado en bienes manufactureros más bien elementales (un tostador, una lavadora) y no sólo en bienes de alta tecnología o inmateriales.

Ambos argumentos señalan que necesitamos entendimientos más complejos de los parámetros y condicionalidades de las economías del conocimiento. Esto a su vez tiene consecuencias para el desarrollo urbano y regional. Hay implicancias de políticas para cada uno de estos argumentos, y ellos pueden ir en direcciones inesperadas o en direccio- 
nes que no corresponden a muchas de las nociones extendidas sobre la economía del conocimiento y las políticas que buscan promoverla.

\section{Escalamiento y sus consecuencias}

Moverse desde la escala de la ciudad hacia la de una región urbanizada altera el análisis. Una región fácilmente contiene sitios que muestran economías de aglomeración y sitios que ofrecen la opción de una dispersión geográfica de actividades. Más allá de esto, las cuestiones del poder y las desigualdades aparecen bastante diferentes cuando se comparan regiones y ciudades. Para focalizar la mirada, la discusión en esta sección del artículo está confinada a ciudades globales y a ciudades-regiones globales. El concepto de ciudad-región global agrega una dimensión completamente nueva a las cuestiones de territorio y globalización ${ }^{2}$. Este tipo de comparación ilustra algunos de los temas desarrollados en la discusión más analítica de las secciones precedentes. Y plantea el argumento en una forma más descriptiva, de esta forma, aun si el lector rechaza la analítica de la sección precedente, aún queda espacio para la empírica.

Una primera diferencia concierne a la cuestión del territorio. La escala territorial de la región es mucho más probable que represente un corte transversal de las actividades económicas de un país que la escala de la ciudad. Por ejemplo, es probable que incluya como variables clave a la manufactura y a un conjunto de sectores económicos estandarizados que se encuentran en el corazón de la economía nacional. Esto a su vez trae consigo una manifestación más benigna de la globalización. El concepto de la ciudad global introduce un énfasis mucho más fuerte en componentes estratégicos de la economía global, típicamente sujetos a economías de aglomeración extremas en los niveles más altos de las funciones de gestión y servicios corporativos especializados; esto a su vez puede conducir a formas extremas de poder y desigualdades en la ciudad global. En segundo lugar, el concepto de ciudad global tiende a tener un énfasis más fuerte sobre la economía en red debido a la naturaleza de las industrias que (2001). tienden a estar localizadas allí: finanzas, medios, y otros servicios especializados. Y en tercer lugar, tiende a enfatizar la polarización espacial y económica debido a la demanda desproporcionada de empleos de ingresos muy altos y muy bajos en estas ciudades, comparadas con lo que sería el caso para la región, que tendría mucho más firmas y empleos de tipo medio.

Con todo, el concepto de ciudad global está más en sintonía con cuestiones de poder y desigualdades y también con cuestiones sobre la naturaleza y especificidades de patrones de urbanización más amplios, una base económica más abarcadora, más sectores medios tanto en hogares como firmas, y por tanto con la posibilidad de tener una distribución de los beneficios económicos más igualitaria bajo las actuales dinámicas de crecimiento económico, incluyendo la globalización financiera. A este respecto, puede decirse que el concepto de ciudad-región global nos permite ver las posibilidades de un tipo de crecimiento más distribuido, una extensión más amplia de los beneficios asociados con el crecimiento económico, incluyendo el crecimiento resultante de la globalización.

En segundo lugar, ambos conceptos tienen un problema de límites de a lo menos dos tipos, el límite de la escala territorial como tal y el límite de la extensión de la globalización en la estructura organizacional de las industrias, órdenes institucionales, lugares y así sucesivamente. En el caso de la ciudad global he optado por una estrategia analítica que enfatice las dinámicas centrales más que la unidad de la ciudad como contenedor -entendiéndolo como una entidad que requiere una especificación de límites territoriales-. El énfasis en las dinámicas centrales y su especialización (tanto en el espacio actual como digital) no resuelve completamente el problema de los límites, pero permite un trade-off relativamente claro entre el énfasis en el núcleo o centro de estas dinámicas y su difusión institucional y espacial. En mi trabajo he buscado abordar ambos lados de este tradeoff, al enfatizar por una parte las industrias más avanzadas y globalizadas, tales como las finanzas, y por otra parte, cómo la economía informal (vista típicamente como local) en las principales ciudades globales es articulada con algunas de las 
industrias líderes. En el caso de la ciudad-región global, no me parece claro cómo Scott (2001) especifica la cuestión de los límites, tanto en su sentido de territorio como en términos de su organización y difusión.

Una tercera diferencia es el énfasis en la competencia y la competitividad, mucho más fuerte en el constructo ciudad-región global. La naturaleza misma de las industrias líderes en las ciudades globales fortalece la importancia de las redes trans-fronterizas y la división especializada de funciones entre ciudades en diferentes países y/o regiones más que la competencia internacional por sí misma. Más aún, aunque la competitividad es una condición necesaria es mucho menos prominente en estos sectores, que tienden a priorizar el "talento" como clave más que la competencia, en contraste con lo que sería desarrollar trenes rápidos regionales donde la cuestión de la competencia (más que talento especulativo, por ejemplo) es esencial. Las finanzas globales y los servicios especializados líderes, que proveen a las firmas y mercados globales -legales, contabilidad, calificadoras de riesgo, telecomunicaciones- constituyen circuitos trans-fronterizos incrustados en redes de ciudades, cada una posiblemente una parte de un país diferente. Es un sistema global de facto, centrado en algo más que competencia y competitividad.

Es menos probable que las industrias que tenderán a dominar las ciudades-regiones globales conformen redes de esta forma. Por ejemplo, en el caso de grandes complejos manufactureros, y de complejos de consumo intermedio o final, la identificación con lo nacional es más significativa, y la a menudo fuerte orientación a los mercados de consumo trae al frente la cuestión de la calidad, precios y la posibilidad de sustitución. Por lo tanto es probable que la competencia y la competitividad sean mucho más relevantes. Adicionalmente, aún cuando hay una transferencia de producción al exterior, y en este sentido una división internacional del trabajo, como en la industria automotriz, este tipo de internacionalización tiende a adoptar la forma de una cadena de producción interna a una firma dada, que hoy en día puede cruzar fronteras. En la medida que la mayoría de las firmas aún tienen sus casas matrices asociadas con una región o país específicos, es probable que la cuestión de la competencia sea prominente y, más importante, situada. Por ejemplo, la industria automotriz de Estados Unidos versus la japonesa, aunque incluso esto está cambiando.

La cuestión de la competitividad de una región está profundamente centrada en sus infraestructuras convencionales -transporte de todo tipo, producción y distribución de agua y electricidad, aeropuertos, y así sucesivamente-. En alguna medida, esto es también una variable crucial en el caso de las ciudades globales, pero es de un tipo mucho más especializado de infraestructuras en estas últimas. La escala regional trae al frente cuestiones de transporte público, construcción de autopistas y aspectos similares que la mirada en la escala de las ciudades globales no tiene. Nuevamente, esto revela en qué medida el concentrarse en la región produce una representación más benevolente de los impactos de la economía global. Es más probable que el concentrarse en la infraestructura regional incluya consideraciones más fuertes sobre las necesidades de las clases medias. En contraste, concentrarse en la ciudad global tendería a destacar las crecientes desigualdades entre sectores y espacios de la ciudad altamente aprovisionados y profundamente en desventaja, y por tanto cuestiones de poder y desigualdades.

Una cuarta diferencia, conectada con la anterior, es que la concentración en las dinámicas de redes trans-fronterizas entre ciudades globales, también nos permite capturar más fácilmente la creciente intensidad de tales transacciones en otros dominios - políticos, culturales, sociales, criminales ${ }^{3}$ - . Hay una evidencia creciente de mayores transacciones trans-fronterizas entre comunidades inmigrantes y sus comunidades de origen y una mayor intensidad en el uso de estas redes una vez que se establecen, incluyendo a actividades económicas hasta ahora no consideradas. También hay evidencia de mayores redes trans-fronterizas para propósitos culturales, como en el caso del crecimiento de los mercados internacionales para el arte y una clase transnacional de restauradores; y para propósitos políticos informales, como en el

\footnotetext{
3 No puedo evitar referirme a un libro que abre nuevos terrenos a este respecto: Hagedorn (2004).
} 
caso del crecimiento de redes transnacionales de activistas en torno de causas medioambientales, derechos humanos, y así sucesivamente. Estas son redes trans-fronterizas mayoritariamente ciudad-ciudad, o, a lo menos, parece ser más simple capturar la existencia y modalidades de estas redes al nivel de la ciudad. Lo mismo puede decirse para las nuevas redes criminales trans-fronterizas. Al tratar con la escala regional no se facilita necesariamente el reconocimiento de la existencia de tales redes desde una región a otra. Es mucho más probable que sea desde una comunidad específica en una región a otra comunidad específica en otra región, neutralizando por tanto el significado de la región como tal.

Una implicancia clave de esta comparación es la necesidad de controlar por algunas de las diferencias inevitables que son función de la escala en sí misma. Hay un riesgo de reificar la organización espacial de un terreno limitado, ya sea una ciudad, una región o una mega-región. La comparación entre una ciudad y una región agrega información importante a nuestros esfuerzos para entender la variabilidad de una localización y las ventajas de proximidad. Pero también es un hecho que la realidad de una mega-región puede descansar en dinámicas que subyacen tanto a la ciudad como a la región.

Parte de la tarea de especificar una mega-región requiere de dar cuenta de estas agudas diferencias dentro de una región y de las posibles dinámicas compartidas subyacentes a estas diferencias: así, la multipolaridad y la dispersión geográfica que caracterizan a estas mega-regiones pueden en parte alimentar también a las economías de aglomeración en las ciudades de estas regiones, emergiendo precisamente de esta dispersión. Una cuestión crítica es si algunas de estas formaciones diversas -multipolaridad, dispersión, aglomeración- pueden ser re-regionalizadas. Esto puede tomar dos formas, una más elemental y una más compleja. La elemental es incrementar el rango de formaciones que podrían ser incorporadas dentro de una mega-región, más que sólo pensar en términos de las actividades de punta de un sector económico u operaciones de una firma, como se hace a menudo. La forma compleja es incrementar el rango de formaciones que son parte de un cierto sector en crecimiento o de una cadena de operaciones multilocacional de una firma. Tal re-regionalización de los componentes del crecimiento económico podría emerger como una ventaja principal de las mega-regiones.

\section{Mega-regiones}

Hay mucho que puede decirse acerca de las mega-regiones. La preocupación aquí es identificar tipos posibles de interacciones económicas interregionales que podrían ser habilitados por la escala mega-regional. El acento se coloca en dos temas clave. Primero, es ver si tales interacciones podrían implicar ir más allá de estilos de planificación económica que buscan capturar sólo los sectores económicos más avanzados, tales como las "economías del conocimiento" y empezar a encontrar valor en aquellas áreas de una región que no son espacios económicos avanzados. Segundo, si esto a su vez, le otorga a las mega-regiones ventajas particulares en la economía global actual. Si ambas situaciones son en efecto el caso, es útil preguntarse de qué forma nuevos tipos de coordinación y gobernanza megaregional podrían ser útiles. El esfuerzo central es considerar los beneficios de las mega-regiones más allá de las tradicionales economías de escala -esto es, más allá de las ventajas del tamaño y de más de lo mismo.

Esta es mi tesis. Una mega-región es una escala que puede beneficiarse del hecho de que nuestras complejas economías contienen diversos tipos de economías de aglomeración y contextos geográficos, desde los más altos (por ejemplo, los servicios especializados corporativos avanzados) a los más modestos (por ejemplo, parques de oficinas suburbanos y manufacturas intensivas en trabajo y de bajos salarios).

Una mega-región puede incorporar esta diversidad en una única mega zona económica. Efectivamente, en principio, podría crear condiciones para el retorno de actividades particulares (no todas) que ahora son transferidas a otras regiones o localizaciones extranjeras. Esto expandiría el proyecto de optimizar el crecimiento más allá de la preferencia usual de sectores estado del arte (tales como parques científicos y de oficinas) e incluir una mayor diversidad de sectores económicos. 
Una segunda dimensión crítica concierne a los efectos de crecimiento resultantes de la interacción de diversos tipos de sitios de una firma. Desde la perspectiva de una mega-región esto implicaría tener tanto las casas matrices como los trabajos rutinarios de bajo costo de una firma, ahora típicamente transferidos a países extranjeros. Esto agregaría aún otra fuente específica de crecimiento para la mega-región, una más allá de la mera suma de los empleos involucrados.

Podríamos especificar empíricamente algo de esto estableciendo si las economías de aglomeración (no sólo las economías de urbanización) importan para desarrollar la organización espacial de una mega-región. El examen de la cuestión de las economías de aglomeración en el periodo actual está enmarcado por dos hechos que están potencialmente en tensión entre ellos. Por una parte, las nuevas tecnologías de información permiten a las firmas dispersarse en una creciente gama de operaciones, ya sea a nivel metropolitano, regional o global, sin perder integración del sistema ${ }^{4}$. Esto tiene el potencial de reducir (aunque no eliminar) los beneficios de las economías de urbanización de tales firmas. Por otra parte, la evidencia muestra claramente aglomeraciones y densidades crecientes en las grandes regiones, incluyendo el aumento de la escala hacia el nivel mega-regional, como ha sido identificado por la Regional Planning Association (RPA) para el caso de los Estados Unidos 5 .

En primer término daré cuenta de la instancia más extrema: firmas globalizadas con una considerable digitalización de sus procesos de producción y sus productos. En este caso, hay considerablemente menos y menos ventajas de aglomeración, especialmente para los sectores más avanzados, típicamente con producción de alto valor, capaces de comprar las últimas tecnologías, y altamente globalizados, esto es, con múltiples operaciones a través del mundo.

Refutando esta explicación de orientación tecnológica, uno puede mostrar cómo y por qué precisamente estas firmas están sujetas a economías

4 Para uno de los mejores conjuntos de datos sobre dispersión a escala global de las operaciones de firmas de servicios corporativos, ver GAWC (1998).

Ver Goldfeld (2007) de aglomeración extremas en algunos -aunque no todos- de sus componentes ${ }^{6}$. Este hecho importa para entender la ventaja de una mega-región debido a que ellas contienen ciudades extremadamente densas con recursos y tipos de talento diversos. Una segunda implicancia para la mega-región es que el carácter multi-sitio de los sectores económicos líderes incluye no sólo ciudades como sitios clave, sino que otros tipos de sitios -algunos con economías de aglomeración medias y aun bajas o sin ellas, pero básicamente áreas subdesarrolladas de bajos costos.

Lo que entrega este significado adicional a las mega-regiones son los efectos de crecimiento resultantes de las interacciones de diversos tipos de sitio de una firma. De esta forma, una de las hipótesis en mi modelo de ciudad global es que las funciones de las casas matrices de una firma se expanden como resultado de la multi-situación de esa firma (ya sea nacional o global) ${ }^{7}$. Mientras más afiliados, puntos de ventas de servicios, y plantas tenga una firma en el mundo, más se expanden sus funciones de gestión central y de servicios. Este es un potencial de crecimiento significativo que puede ser endogeneizado dentro de una mega-región. Este efecto de crecimiento va más

Un tema paralelo, no completamente abordado en este artículo, es la articulación de la conectividad técnica con la conectividad social. Ver, por ejemplo, García (2002).

Este es un tipo de economía de aglomeración que he encontrado en mi investigación sobre ciudades globales, pero que también puede ser aplicado a escalas nacionales o regionales. La hipótesis era que a mayores capacidades de dispersión tenga una firma, más estará sujeta a las economías de aglomeración en algunos de sus componentes, notablemente en sus funciones centrales de alto nivel. En Sassen (2001), dentro del nuevo prefacio, se encuentra una breve explicación de las nueve hipótesis que especifican el modelo de la ciudad global. Son las funciones más especializadas pertenecientes a las firmas más globalizadas, las cuales están sujetas a las más elevadas economías de aglomeración. Las complejidades de las funciones que necesitan ser producidas, la incertidumbre en los mercados en que tales firmas están involucradas, y la creciente importancia de la velocidad de estas transacciones, es una mezcla de condiciones que constituyen una nueva lógica para la aglomeración; no es la lógica posicionada en los modelos antiguos, donde el peso y la distancia (costos de transporte) eran vistos como determinantes de la forma de las economías de aglomeración. La mezcla de firmas, talentos, experticia en amplio rango de campos especializados, genera un cierto tipo de denso medioambiente que funciona como una economía del conocimiento estratégica donde el todo es más que la suma de (aun de sus más finas) partes. 
allá de la mera adición de empleos resultantes de la captura por parte de esa mega-región de más sitios de la cadena de operaciones de una firma: también agrega una compleja dinámica de redes que empieza a articular partes muy diversas de una mega-región.

Ahora la cuestión se transforma en si una mega-región puede buscar albergar un mayor rango de operaciones constitutivas de la cadena de valor de una firma -desde aquellas sujetas a economías de aglomeración a aquellas que no muestran tales economías-. Hablando en términos prácticos esto apunta a la posibilidad de traer hacia (en algunos casos regresar a) una mega-región algunos de los servicios y bienes generadores de empleo y operaciones hasta ahora transferidos para lograr salarios más bajos y menos regulaciones. ¿Pueden ellos ser reinsertados en áreas de bajo crecimiento y bajo costo de una mega-región? ¿Qué tipo de planificación implicaría, y pudiera ser implementada, de manera de optimizar los beneficios para todos los involucrados, no solo firmas sino también trabajadores y localidades? Esto expandiría el proyecto de optimizar el crecimiento más allá de los sospechosos usuales - parques científicos y de oficinas- y moverse a través de sectores mucho más diversos. Usaría la palanca de la escala mega-regional para proveer espacios diversos que abastezcan diferentes tipos de actividades, desde aquellas sujetas a altas economías de aglomeración a aquellas sujetas a bajas economías de aglomeración. Finalmente, la escala mega-regional ayudaría a optimizar los efectos del crecimiento que surgen de las interacciones de algunas de estas economías de aglomeración. Este efecto de crecimiento sería optimizado re-regionalizando algunas de las operaciones de bajo costo de firmas que hoy se dispersan a través del país y/o el mundo.

Si este tipo de hipótesis captura en efecto un potencial de las mega-regiones, sería el inicio de una nueva historia económica. La posibilidad de este tipo de potencial es fácilmente obscurecida por la prevalencia de indicadores, datos y políticas de nivel nacional. La identificación de la mega-región produce un nivel intermedio, uno que aun cuando parcialmente dependiente de políticas nacionales macro también introduce un conjunto de temas mucho más específico en el paisaje económico ${ }^{8}$. Una mega-región puede combinar una proporción mucho mayor de economías diversas, que son una gran parte de nuestra era actual, y puede incorporar efectos de crecimiento que emergen por la interacción de estas economías diversas.

Esta forma de pensar acerca de la escala mega-regional hace surgir la importancia de la planificación y la coordinación para asegurar resultados óptimos para todas las partes involucradas, incluyendo el reto de asegurar los beneficios buscados por las firmas cuando ellas dispersan sus operaciones hacia áreas de bajos salarios. Esto podría funcionar para algunos tipos de sectores económicos y tipos de firmas, no para todos. Algunas actividades que han sido transferidas hacia otros países no han funcionado y han debido ser repatriadas -ellas van desde agentes de ventas de aerolíneas a tipos particulares de trabajo de diseño en industrias tan diversas como vestuario y alta tecnología-. Pero muchas de estas actividades transferidas lo están haciendo bien en lo que a las firmas concierne. Se necesita investigación y políticas específicas para establecer el qué, cómo y dónde de las ventajas para firmas pertinentes de acceder a trabajadores de bajos salarios en los Estados Unidos; lo cual incluye entender cómo la localización de estos componentes de bajo costo en la mega-región, donde una firma dada localiza su casa matriz, puede compensar los mayores costos. Esto puede requerir inversiones mega-regionales para desarrollar áreas de bajo costo para tales empleos -una especie de zona empresarial rural.

\footnotetext{
8 La región, el área metropolitana y la ciudad, son escalas que permiten al investigador capturar los muchos circuitos altamente especializados que están comprometidos por "la" economía global. Circuitos diferentes contienen agrupamientos diferentes de regiones y ciudades. Visto en esta forma, la economía global se transforma en concreta y específica, con una geografía bien definida. Bienes y servicios son redistribuidos a un vasto número de destinos, sin importar cuán pocos sean los puntos de origen en algunos casos. Con la globalización, esta capacidad de redistribuir globalmente ha crecido agudamente. Concentrándose en una escala como la región y en los diversos tipos de espacios económicos que contiene, es posible capturar múltiples de estos puntos de redistribución, así como puntos de origen. Para un tratamiento definitivo de algunos de estos temas en la medida que se apliquen a las industrias de servicios, ver Taylor (2004).
} 
Existe posiblemente a un nivel macro un efecto positivo de repatriar algunos de estos empleos, si la carrera hacia abajo puede ser evitada, y un cierto nivel de capacidad de consumo asegurada por medio de salarios razonables o subsidios indirectos particulares. Esto trae un efecto positivo específico para áreas menos desarrolladas de una mega-región, en la medida que los hogares de bajos salarios tienden a gastar una proporción mucho mayor de su ingreso en sus lugares de residencia -ellos carecen del capital de inversión de los estratos de ingresos superiores, quienes pueden terminar asignando la mayoría de sus ingresos en inversiones en el extranjero-. Finalmente, esto también es un elemento en el reto mayor de asegurar resultados más equitativos 9 . Es importante preguntarse acerca de los efectos distributivos de la configuración actual y de los (potenciales) resultados optimizados descritos en este artículo; existe suficiente evidencia sobre cómo una extrema mala distribución de los beneficios del crecimiento económico no es deseable en el largo plazo.

Estas formas de especificar el significado de una mega-región (o región) nos lleva desde un enfoque "estático" a un concepto más dinámico de mega-región: más allá de las ventajas de urbanización, una mega-región bien puede resultar una escala suficientemente grande para optimizar los beneficios de contener economías de aglomeración diversas e interactivas.

\section{Proximidad y sus ventajas: ¡aadecuadas para las mega-regiones?}

Las actuales tecnologías de información y capacidades de comunicación pueden entregar integración sistémica no importando cuán distantes puedan estar las operaciones de una firma. Si todas las firmas y sectores pudieran comprar y usar estas tecnologías para reducir o neutralizar las ventajas de las economías de aglomeración, el resultado sería un declive de los beneficios de localización que otorgan las economías de aglomeración, principalmente las ciudades globales. Tal declive se vería aún más fortalecido por la posibilidad de un (2005) incremento de la proporción de "e-conmutadores" -trabajo en línea desde el hogar.

En su versión más extrema, este escenario sugiere que las ventajas de localizarse en una mega-región estarían limitadas por las economías de urbanización. Las firmas necesitan localizarse en alguna parte, al igual que sus trabajadores; y ¿por qué no en una mega-región? y, segundo, sin importar que hayan o no ventajas locacionales específicas mega-regionales, habría una demanda por proveedores locales de bienes intermedios y finales y servicios que necesitan ser producidos in situ -que no pueden ser importados desde algún lugar lejano, o por lo menos no aún-. El sólo hecho del crecimiento de la población es suficiente para alimentar este tipo de demanda.

Bajo estas condiciones, la especificidad de ventajas locacionales mega-regionales proviene del hecho de que hay un mercado, o más aún un conjunto de mercados, para bienes y servicios requeridos, tanto finales como intermedios. Transporte, vivienda, edificios de oficinas, edificios para factorías, y así sucesivamente, encuentran una demanda real por parte de hogares, gobiernos y sus múltiples instancias, desde escuelas a cortes, instituciones de todo tipo, y firmas. A medida que crecen la población y la distancia, emergen nuevos tipos de demanda: como trenes rápidos, super-carreteras, y más diversidad en la oferta residencial. Sin importar cuán complejos sean los componentes de esta demanda final e intermedia esto es, en algunas formas, una versión muy elemental de las ventajas de la escala mega-regional

\section{¿Existen ventajas más complejas para la localización mega-regional?}

El punto de partida es que la localización es una variable. La firma que puede reemplazar las ventajas de aglomeración con las nuevas tecnologías de información representa un caso extremo en la ventaja de localización: muestra menores, si es que algunas, economías de aglomeración. El hecho del crecimiento de la población y la necesidad asociada de vivienda, y todo lo que viene asociado a ellos, es en muchas formas el mismo tipo de argumento sobre esa variable; la diferencia es que está sujeta a las ventajas de urbanización. Al 
otro extremo de estos dos casos se encuentran las economías de aglomeración altas. Esto está bien establecido para ramas muy especializadas de las finanzas globales y las ramas más innovadoras de las industrias de alta tecnología, siendo las ciudades globales y los silicon valleys las formas espaciales emblemáticas respectivas.

Las ventajas de localización en una megaregión en estos tres tipos diversos de instancias necesitan ser especificadas empíricamente. En los primeros dos casos la ventaja particular es una noción amplia y geográficamente expandida, de las ventajas de urbanización -el conjunto de infraestructuras, mercados de trabajo, edificios, viviendas, recursos institucionales básicos, amenidades-. En una mega-región estas ventajas se esparcen sobre un vasto terreno geográfico, engendrando sus componentes específicos propios de demanda final e intermedia, por ejemplo sistemas de transporte rápido.

La cuestión entonces se convierte en cómo incrementar estas ventajas de urbanización, cómo evitar los excesos del crecimiento, expansión y dispersión y sus efectos negativos sobre la congestión, precios, costos etc. Si son los mercados o la planificación los instrumentos deseables para optimizar las economías de "urbanización" (entendidas en sentido amplio de que ellas incluyen no sólo localizaciones urbanas) dependerá de un conjunto de variables. Una línea potencialmente innovadora de análisis es el grado en el cual la mega-región permite nuevas formas de tratar las externalidades negativas.

Por otra parte, en el caso de sectores sujetos a economías de aglomeración, bien puede ser el caso de que la mega-región no contenga ventajas distintivas sobre otras escalas, principalmente áreas metropolitanas o ciudades. Lo que estos sectores parecen necesitar es un conjunto de recursos correlacionados con alta densidad y, en el extremo, lugares centrales muy densos -tales como las ciudades globales y los silicon valleys-. La cuestión entonces se convierte en si existe uno o varios tipos de economía de aglomeración que puedan ser desarrolladas e incrementadas a la escala de la mega-región. Las mega-regiones contienen localizaciones de alta densidad; una firma sujeta a economías de aglomeración puede muy bien encontrar en una de estas localizaciones un mix de recursos diversos y altamente especializados que necesita. Pero, ¿̨necesita una mega-región completa adjunta a esa localización?

Aquí se abre un nuevo territorio teórico y empírico. Una hipótesis crítica desarrollada para el modelo de ciudad global es que en la medida que la dispersión geográfica de las operaciones de las firmas globales (ya sean factorías, oficinas o venta de servicios) alimente la complejidad de las localizaciones de las casas matrices, a mayor globalización de la firma mayores serán las ventajas que sus matrices deriven de localizaciones centrales $(\text { ver nota })^{10}$. Una inferencia es que la ventaja de la escala mega-regional es que puede, en principio, contener tanto las sedes centrales y a lo menos algunas de estas operaciones dispersas de las firmas globales. En otras palabras, la mega-región es una escala en la cual tales firmas en realidad también pueden "transferir empleos" y suburbanizar funciones centrales -en ambos casos en la búsqueda de menores costos- y beneficiarse de la ciudad o ciudades más grandes de la región, incluyendo en ambos casos, ciudades globales, o ciudades con funciones significativas de la ciudad global.

¿Pueden las mega-regiones entregar ventajas particulares si ellas también pueden contener algunas de las operaciones geográficamente dispersas de una firma? La evidencia muestra que crecientemente la organización espacial de firmas y sectores económicos contiene tanto puntos de concentración como de dispersión espacial.

10 Pero hay una advertencia. Una segunda hipótesis clave usada para especificar el modelo de la ciudad global es que, mientras más sedes centrales en realidad compren algunas de sus funciones corporativas a sectores de servicios especializados, más que producirlos internamente, mayores serán sus opciones locacionales. Entre estas opciones está la de salir de las ciudades globales, y más genéricamente, salir de medio ambientes urbanos densos. Esta es una opción precisamente debido a la existencia de un sector de servicios especializados al productor en red que puede crecientemente manejar algunas de las operaciones globales más complejas de firmas y mercados. En mi análisis, es precisamente esta capacidad especializada de manejar las operaciones globales de firmas y mercados lo que distingue la función de producción de la ciudad global, y no el número en sí mismo de sedes corporativas centrales de las mayores firmas del mundo, como se sugiere a menudo. 
Más aún, la evidencia también muestra que en muchos casos estos puntos de concentración espacial contienen segmentos de una cadena de operaciones de una firma que muestran más bien fuertes economías de aglomeración. Una tendencia subyacente (y disciplinante), que se volvió visible ya en los años 70, es que la concentración espacial es más costosa para muchas firmas, de manera que la presión es a dispersar cualquier operación que pueda ser dispersada: Esto contrasta con periodos previos, cuando aún las sedes centrales tenían todas las funciones en un solo lugar. Esta dispersión de las operaciones de una firma puede ocurrir a nivel regional, nacional y/o global, y las aglomeraciones pueden variar agudamente en contenido y en las especificidades de las formas espaciales correspondientes ${ }^{11}$. Por ejemplo, solo para referirnos a casos de Estados Unidos, el centro financiero de Chicago, Hollywood en Los Ángeles, Silicon Valley en el Norte de California, cada uno entrega economías de aglomeración a firmas y sectores que también contienen a menudo una vasta dispersión geográfica de algunas de sus otras operaciones.

Concentrarse en el hecho de que muchas actividades económicas contienen tanto concentración espacial como cadenas de operación translocal nos ayuda a situar la especificidad de una ciudad, área metropolitana, o una mega-región en una condición sistémica mucho más amplia, una que puede incluir tanto puntos sujetos a agudas economías de aglomeración y puntos no sujetos a ellas -cuando la dispersión geográfica es una ventaja-. Lo que ofrece la mega-región en este contexto es un mayor rango de tipos de localización que en una ciudad o un área metropolitana -desde localizaciones sujetas a altas economías de aglomeración hasta localizaciones donde la ventaja surge de la dispersión.

Avanzando un paso más allá, la mayoría de las firmas globalizadas e innovadoras eran caracterizadas por el hecho de que las economías de aglomeración son en parte ellas mismas función de la dispersión. Esto es, mientras más globalizada y, por tanto, geográficamente dispersas las

11 Uno de los mejores y más detallados análisis que compara dos formatos diferentes de distritos de alta tecnología es Saxenian (1996). operaciones de una firma, más probable resulta la presencia de economías de aglomeración en momentos particulares (la producción de funciones de sedes centrales principales) de la cadena de operaciones de esa firma ${ }^{12}$. Para los propósitos de este ensayo, se subraya el hecho de una dinámica única con especializaciones diversas, es decir, tanto aglomeración como dispersión, a través de diversas escalas geográficas. Una mega-región podría ser entonces concebiblemente una escala que pueda incorporar estos diferentes contextos.

Una forma de especificar empíricamente algo de esto es proponer una relación directa entre el crecimiento en una localización de actividades económicas dispersas de una mega-región y las localizaciones de actividades sujetas a economías de aglomeración. Mientras más crezca la primera, más crecerá la última. El truco es entonces maximizar la co-presencia en una mega-región de estos dos tipos de localizaciones. Es importante destacar que esto también plantea límites a las ventajas de las economías de urbanización. Estas últimas resultan ser una curva: ellas crecen con la escala, pero sólo hasta cierto punto. Este punto está típicamente especificado en términos de externalidades negativas. Pero lo que mis análisis sugieren sobre esto es que este punto puede ser también especificado en términos de las pérdidas económicas derivadas de no permitir el "desarrollo" de localizaciones dispersas; como esto significa localizaciones donde las firmas puedan enviar sus empleos de bajos salarios, con bajos requerimientos educacionales, se iría en contra de los objetivos prevalecientes de la mayoría de los lugares, que es obtener empleos de altos salarios y altamente intensivos en capital. Finalmente, si lo que hoy es el punto sobre la curva donde aparecen las externalidades negativas familiares (por ejemplo, exceso de congestión) puede hacerse coincidir con aquel desarrollo de "localizaciones dispersas" para las firmas, por tanto

$12 \mathrm{Y}$, en efecto, ciertas formas muy contemporáneas de dispersión son una función de capacidades particulares desarrolladas en contextos marcados por altas economías de aglomeración (ejemplificadas por las ciudades globales). Y ellas no sólo están ocurriendo en la estrechamente entendida esfera de la economía: es posible identificar el crecimiento de una clase de restauradores internacionales, y de grandes museos que permiten que sus colecciones más valiosas viajen a exhibiciones en otros países. 
se puede hacer una ventaja de lo que hoy es una desventaja.

En términos prácticos hay claramente enormes retos para que una mega-región logre este tipo de co-presencia, maximizando el grado en el cual una mega-región puede contener tanto la aglomeración como los segmentos dispersos de la cadena de operaciones de una firma. De partida, es una proposición contraintuitiva y que va a contrasentido. No es fácil ver por qué los espacios económicos altamente dinámicos de una megaregión (las áreas centrales de sus ciudades globales y silicon valleys), centrados en las sedes centrales de las firmas nacionales y globales, puedan realmente ser alimentados y fortalecidos parcialmente por el desarrollo de "localizaciones dispersas" de esas mismas firmas. El pensar en desarrollar tales "localizaciones dispersas" como una forma de abordar las principales externalidades negativas puede hacerlo más aceptable para los escépticos: se podría asimismo optar por actividades que se benefician de ordenamientos geográficamente dispersos, una vez que se han resuelto las desventajas de el exceso de congestión. Pero una opción en este momento es por supuesto pensar en cosas tales como campos de golf o viviendas lujosas extra urbanas. Este es un argumento que podría ser debatido ya que las mega-regiones tienden a contener mucha tierra que no es óptima para tales usos, pero que podría serlo para el desarrollo de "localizaciones dispersas". Más aún, y crítico para algunas de mis preocupaciones sustantivas por las áreas en desventaja, ellas podrían beneficiarse de tales desarrollos, si se logra evitar una carrera hacia abajo.

La mega-región puede ser vista entonces como una geografía escalar interesante: puede contener algunas de las operaciones dispersas de una firma que alimenten estas nuevas formas de economías de aglomeración. Podría sugerir que la planificación regional estratégica podría apuntar a maximizar la combinación de lógicas locacionales diferentes. Es esta combinación lo que en mi opinión marca la especificidad del "proyecto" contenido en la noción de mega-región. Este tipo de región no puede ser visto simplemente como un resultado: allí está, y encontremos un paquete que junte todo esto bajo un paraguas. Como un término, la mega-región tiene una cierta pasividad asociada a ella. Las economías de aglomeración mega-regionales, por otra parte, son una noción que captura una dinámica que produce resultados. Esto a su vez abre una agenda de investigación: por ejemplo, para entender a qué escala territorial tales economías se fortalecen o debilitan. Sin embargo, la mega-región es un concepto pegadizo, que describe una condición auto-evidente, y en este sentido es un término aceptable y digerible (algo que no puede decirse de las economías de aglomeración mega-regionales).

La hipótesis puede ser esquematizada como sigue: mientras más sea moldeada una región urbana por las nuevas dinámicas económicas, más su organización espacial implicará economías de aglomeración como una función de la dispersión geográfica de las actividades económicas bajo condiciones de integración sistémica, sin importar la escala -regional, nacional o global.

La siguiente sección examina un aspecto crítico de tal co-presencia: ¿la dispersión geográfica fortalece a las economías de aglomeración? Tomo el caso extremo -las firmas más digitalizadas y globalizadas- como un experimento natural para entender los parámetros de la articulación entre la dispersión geográfica y las economías de aglomeración, y que significaría regionalizar esta articulación.

\section{¿Fortalece la dispersión geográfica a las economías de aglomeración?}

Un buen punto de partida es concentrarse en por qué las firmas más avanzadas de la economía del conocimiento están sujetas a lo que a menudo parecen economías de aglomeración extremas, aun cuando ellas funcionan en mercados electrónicos y producen productos digitales. Otra forma de hacer la pregunta es concentrándose en los más globalizados y digitalizados del conjunto de sectores asociados al conocimiento: ¿por qué las finanzas globales necesitan centros financieros? $\mathrm{O}$, más en general, ¿’por qué los servicios corporativos globales altamente especializados que pueden ser transmitidos digitalmente prosperan en densos centros de ciudades? Esto significa incorporar al lugar en un análisis de las economías del conoci- 
miento que usualmente es examinado en términos de sus movilidades y compresión espacio-tiempo. Observando a la economía del conocimiento y, más en general, a las firmas globales, desde la óptica de las regiones, ciudades, áreas metropolitanas, introduce variables diferentes ${ }^{13}$.

Se sabe mucho sobre la riqueza y poder de las firmas globales de hoy día. Su ascensión en un mundo globalizado ya no es sorprendente. De manera similar, con las nuevas tecnologías de información y comunicación, se ha otorgado mucha atención a sus enormes capacidades para conducir operaciones en el mundo entero sin perder un control central. Menos claro resulta el hecho de por qué las ciudades o regiones deberían importarle a las firmas globales, particularmente aquellas que son suficientemente ricas para comprar cualquier innovación técnica que las libere del lugar, sus fricciones y sus costos. Hay varias lógicas que explican por qué las ciudades son importantes para las firmas y sectores más globalizados (dispersos) y digitalizados en una forma en que no ocurría incluso en los '70. Aquí consideraremos tres de estas lógicas ${ }^{14}$.

La primera es que no importando cuán intensiva sea una firma en el uso de tecnologías digitales, su lógica operacional no es lo mismo que la lógica del ingeniero que diseñó esa tecnología. Confundir estas dos lógicas potencialmente muy diversas ha producido un conjunto de malas interpretaciones. Cuando las nuevas tecnologías de información y comunicación (TIC) comenzaron a ser utilizadas ampliamente en los '80, muchos expertos "pronosticaron" el fin de las ciudades como espacios estratégicos para las firmas en sectores avanzados. Muchos sectores rutinizados dejaron las ciudades y muchas firmas dispersaron sus operaciones más rutinarias a escala regional, nacional y global. Pero los sectores y firmas más avanzadas siguieron expandiendo sus operaciones de mayor nivel en tipos particulares de ciudades.

13 Este lente espacial debe ser también distinguido del ángulo más común de firmas y mercados. Ver, por ejemplo, Dieter (2005). sen (2006a)
¿Por qué estaban tan equivocados esos expertos? Ellos pasaron por alto un factor clave: cuando las firmas y mercados usan estas nuevas tecnologías lo hacen con objetivos financieros o económicos en mente, y no con los objetivos del ingeniero que diseñó la tecnología. La lógica de los usuarios puede frustrar o reducir completamente las capacidades técnicas de la tecnología ${ }^{15}$. Cuando las firmas y mercados dispersan globalmente muchas de sus operaciones con la ayuda de las nuevas tecnologías, la intención no es renunciar al control de esas operaciones. La intención es mantener el control de los problemas de más alto nivel y ser capaces de apropiarse de los beneficios o ganancias de esa dispersión ${ }^{16}$. En la medida que el control central es parte de la globalización de las actividades, sus funciones de sedes centrales de mayor nivel en realidad se han expandido debido a que es simplemente más complicado y riesgoso funcionar en 30 ó 50 o más países, cada uno con distintas leyes, reglas contables y culturas empresariales.

Como estas tecnologías son crecientemente útiles para mantener un control centralizado sobre las operaciones globalmente dispersas, sus usos también han fortalecido la expansión de las operaciones centrales. El resultado ha sido un incremento de la presencia de las operaciones de alto nivel en las ciudades más grandes y un crecimiento de la demanda por servicios profesionales de alto nivel y altos salarios, ya sea producidos internamente o comprados a firmas de servicios especializados. De esta forma, mientras más permitan estas nuevas tecnologías la dispersión geográfica global de las actividades corporativas, ellas producen más densidad y centralidad al otro extremo -las ciudades donde las funciones de sedes centrales se realizan.

Una segunda lógica que explica las ventajas en curso de la aglomeración espacial tiene que ver

15 Para una explicación detallada de esta frustración de lógicas técnicas por lógicas de usuarios económicos, financieros o, para estos efectos, culturales y políticos, ver Sassen (2006a).

16 Las multinacionales de hoy en día tienen por sobre un millón de afiliados a lo largo del mundo. Los afiliados son solo un modo de operaciones globales. Para detalles empíricos sobre el rango de formatos de operaciones globales, ver Sassen (2006b), Taylor (2004) y World Federation of Exchanges (2007). 
precisamente con el nivel de complejidad y especialización de las funciones centrales. Estas crecen con la globalización y con la velocidad adicional que permiten las TICs. Como resultado, las firmas globales crecientemente necesitan comprar los servicios más especializados financieros, legales, contables, consultorías y otros tipos. Estas firmas de servicios requieren hacer los trabajos más difíciles y especulativos. Crecientemente son estas firmas de servicios corporativos las que muestran economías de aglomeración, ya que su trabajo se beneficia de estar en medio ambientes complejos que funcionan como centros de conocimiento, debido a que ellos contienen muchas otras firmas especializadas y profesionales de alto nivel con una experiencia mundial. Las ciudades son tales medio ambientes, siendo las cuarenta mayores ciudades globales en el mundo las más significativas de estos medio ambientes, pero con un número creciente de otras ciudades en el mundo fuertes en elementos particulares de tales medio ambientes. En síntesis, las ciudades o lugares centrales proveen la conectividad social que permite a una firma maximizar los beneficios de su conectividad tecnológica ${ }^{17}$.

Una tercera lógica concierne al significado de la información en una economía de la información. Hay dos tipos de información. Uno es el dato, que puede ser complejo, aunque es un conocimiento estándar: el nivel al cual cierra la bolsa de valores, la privatización de una empresa pública, la quiebra de un banco. Pero hay un tipo mucho más difícil de "información", semejante a una interpretación/ evaluación/juicio. Supone negociar una serie de datos en una serie de interpretaciones de un mix de datos con la esperanza de producir un dato de mayor orden. El acceso al primer tipo de información es ahora global e inmediato (aun cuando a menudo de alto costo) desde casi cualquier lugar en el mundo altamente desarrollado y crecientemente en el resto del mundo gracias a la revolución digital.

Pero es el segundo tipo de información el que requiere de una complicada mixtura de elementos -la "infraestructura social" para la conectividad global- que le otorga a los principales centros

17 Para un examen detallado de la importancia de la escala subnacional para los mercados globales, ver Harvey (2007). financieros un liderazgo de punta. Cuando las formas más complejas de información necesarias para ejecutar los principales acuerdos internacionales no pueden ser conseguidas de bases de datos existentes, sin importar cuánto uno pueda pagar, entonces uno necesita elaborar esa información; se convierte en parte del proceso de producción de las firmas de servicios corporativos especializados; incluyendo servicios financieros tanto como proveedores de servicios y como firmas por sí mismas. Esa elaboración incluye como componentes críticos la interpretación, inferencia y especulación. Llegado este punto, uno necesita una vuelta de la información social y las interpretaciones de facto e inferencias asociadas que provienen de transferir información entre personas talentosas e informadas. Es la importancia de este insumo lo que le ha dado una importancia completamente nueva a las agencias calificadoras de riesgo, por ejemplo. Parte de la calificación tiene que ver con interpretar e inferir. Cuando esta interpretación se convierte en "autorizada" entonces se convierte en "información" disponible para todos. Para las firmas especializadas en estos complejos dominios, donde las calificadoras de riesgo son sólo uno de estos insumos, la elaboración de información autorizada necesita ser parte del proceso de producción interno o comprado a firmas especializadas. Este proceso de transformar inferencias/interpretaciones en "información" requiere de una combinación excepcional de talentos y recursos. Las ciudades son un medio ambiente complejo que puede proveer esta combinación.

La implicancia clave de este análisis para las mega-regiones es la posibilidad de contener tanto las operaciones dispersas de una firma (a lo menos algunas de ellas) como operaciones de sedes centrales. Los efectos retroalimentadores de contener ambos tipos pueden ser significativos, alimentando simultáneamente el crecimiento de áreas marginales de bajo costo de una mega-región y de sus ciudades globales, o ciudades, que son centros de negocios nacionales.

\section{La continua importancia de los lugares centrales}

Las ciudades han provisto históricamente a las economías, políticas y sociedades nacionales 
de algo que puede ser pensado como centralidad. La forma urbana usual para la centralidad ha sido la densidad, específicamente el centro denso de la ciudad. Las funciones económicas entregadas a través de la densidad urbana en las ciudades han variado a lo largo del tiempo. Pero es siempre una variedad de economías de aglomeración, sin importar cuánto varíe su contenido dependiendo del sector involucrado. Mientras que el sector financiero es bastante diferente del sector cultural, ambos muestran economías de aglomeración; pero el contenido de estos beneficios puede variar agudamente. Una de las ventajas de la densidad urbana central es que ha ayudado históricamente a resolver el riesgo de variedad insuficiente. Trae consigo mercados de trabajo diversos, redes de firmas y colegas diversas, enormes concentraciones de tipos diversos de información sobre los últimos desarrollos, mercados diversos. Las nuevas tecnologías de información y comunicación (TICs) deberían haber neutralizado las ventajas de la centralidad y la densidad. Sin importar dónde esté una firma o un profesional, debería haber acceso a muchos de los recursos necesarios. Pero en los hechos, las nuevas TICs no han eliminado las ventajas de la centralidad y la densidad, y por tanto el rol distintivo de la ciudades para las firmas globales líderes ${ }^{18}$.

Aun cuando mucha de la actividad económica se ha dispersado, los centros de un creciente número de ciudades se han expandido físicamente, por momentos simplemente esparciéndose y por momentos en una moda multi-nodal. El resultado es un nuevo tipo de espacios centrales en estas ciudades y sus áreas metropolitanas que se han expandido físicamente en las últimas dos décadas, un hecho que actualmente puede ser medido, y que puede asumir formatos más variados. El terreno geográfico para estas nuevas centralidades no es simplemente aquel del centro de la ciudad: puede ser metropolitano e incluso regional. En este proceso, el espacio geográfico en una ciudad o área metropolitana que se centraliza, a menudo crece más densamente si se mide en número de firmas aunque no necesariamente en hogares, de lo que era en los años 60 y 70. Esto vale para ciudades tan diferentes como Zurich y Sydney, Sao Paulo

\footnotetext{
18 Ver, por ejemplo, Rutherford (2004).
}

y Londres, Shangai y Buenos Aires (pero la densidad poblacional no es necesariamente el mejor indicador para este tipo de densidad).

La tendencia global de los nuevos espacios centralizados construidos y reconstruidos sugiere un giro irónico de eventos para el impacto de las TICs sobre la centralidad urbana. Claramente, la dispersión espacial de actividades económicas y trabajadores a nivel metropolitano, nacional y global que se empezó a acelerar en los 80 en realidad es la mitad de la historia de lo que está pasando. Nuevas formas de centralización territorial de la gestión y operaciones de control de alto nivel han aparecido junto a estas dispersiones espaciales bien documentadas. Los mercados nacionales y globales, así como las operaciones integradas globalmente requieren lugares centrales donde se lleve a cabo el trabajo de la globalización, como fue analizado en la sección precedente.

La centralidad sigue siendo un aspecto clave en la actual economía global. Pero hoy en día ya no existe una relación directa única entre centralidad y entidades geográficas tales como el centro de la ciudad, o el distrito central de negocios (DCN). En el pasado, y de hecho hasta hace pocos años, la centralidad era sinónimo del centro de la ciudad o el DCN. Hoy, parcialmente como resultado de las nuevas TICs, el correlato espacial del "centro" puede asumir varias formas geográficas, desde el DCN, el área metropolitana, a la nueva malla global compuesta por ciudades globales ${ }^{19}$.

Espacios urbanos, metropolitanos y regionales particulares se están transformando en concentraciones masivas de nuevas capacidades técnicas. Un creciente número de edificios son los sitios para una multiplicación de tecnologías interactivas y de distribución de computadores. Asimismo, infraestructuras de comunicación globales particulares están conectando conjuntos específicos de edificios a lo largo del mundo, produciendo una geografía interactiva altamente especializada, donde las firmas globales están dispuestas a pagar un alto premio para localizarse en ellos. Por ejemplo, la red global de negocios de ATT ahora conecta alrededor de 485.000 edificios en todo el mundo;

19 Para un completo desarrollo de estos patrones, ver Sassen (2006b). 
esta es una geografía específica que actualmente fragmenta a las ciudades donde se localizan estos edificios en la medida que se requiere estar en un edificio "miembro" para acceder a la red. Las áreas más altamente valoradas de las ciudades globales, particularmente los centros financieros, ahora contienen infraestructuras de comunicación que pueden ser separadas del resto de la ciudad, permitiendo un continuo mejoramiento sin tener que dispersarlas al resto de la ciudad. Ellas contienen capacidades técnicas particulares, tales como marcos de confianza, las cuales el resto de la ciudad no posee. Al multiplicar este caso por miles de firmas multinacionales comenzamos a tener una idea de esta nueva conectividad inter-ciudad, en gran parte invisible para el residente promedio.

Una pregunta relevante es si algunas de estas operaciones trans-locales están en realidad localizadas dentro de alguna de las mega-regiones que conciernen a este ensayo. Esta es una pregunta empírica, pero con implicancias para las políticas y la planificación. De manera similar, si estos espacios de centralidad globalmente en red son vistos como plataformas para operaciones globales de firmas y mercados, resulta importante preguntarse si los tipos de componentes de estas plataformas están contenidos dentro de una cierta mega-región. Finalmente, estas plataformas consisten de una variedad de espacios geográficos subnacionales específicos pero también espacios electrónicos. Por lo tanto, es importante preguntarse sobre cuáles son las implicancias para las mega-regiones del hecho de que un creciente número de escalas subnacionales -desde las ciudades hasta precisamente tales mega-regiones- emergen como territorios estratégicos que contribuyen a articular una nueva economía política global, y una nueva economía política regional y nacional.

\section{Redes transfronterizas: una forma especial urbanizada}

Una forma de pensar acerca de la economía global es en términos de los varios circuitos altamente especializados que la conforman. Circuitos diferentes contienen grupos diferentes de países y ciudades. Visto en esta forma, la economía global se vuelve concreta y específica, con una geografía bien definida. Los commodities comercializados globalmente -oro, mantequilla, café, petróleo, semillas de flores- son redistribuidos a un vasto número de destinos, sin importar cuán pocos sean los puntos de origen en algunos casos. Con la globalización, esta capacidad de redistribuir globalmente ha crecido velozmente.

Estos circuitos son multidireccionales y cruzan el mundo, alimentando la geografía inter-ciudades con nodos estratégicos esperados e inesperados. Por ejemplo, Nueva York es el mercado global líder para comercializar instrumentos financieros vinculados al café, aun cuando no cultiva ni un solo grano. Sin embargo, un centro financiero mucho menor, Buenos Aires, es el mercado global líder de instrumentos financieros vinculados a las semillas de flores. Ciudades localizadas en circuitos globales, ya sean muchas o pocas, se convierten en parte de distintas, y a menudo altamente especializadas, geografías inter-ciudades. De esta forma, si uno quiere seguir los circuitos globales del oro como instrumento financiero, son Londres, Nueva York, Chicago y Zurich, los que dominan. Pero si se sigue el comercio directo del metal, Johannesburgo, Mumbai, Dubai y Sydney aparecen todas ellas en el mapa.

Este sistema en red también alimenta movilidades innecesarias, debido a que la economía intermediaria de servicios especializados prospera con las movilidades. Así, en el caso de la economía del Reino Unido, un estudio de la New Economic Foundations y la Open University de Londres, encontró que en 2004, el Reino Unido exportó 1.500 toneladas de papas frescas a Alemania e importó 1.500 toneladas del mismo producto y del mismo país; también importó 465 toneladas de pan de jengibre pero exportó 460 toneladas del mismo producto; y envió 10.200 toneladas de leche y crema a Francia, aunque importó 9.900 toneladas de los mismos bienes desde Francia

Una forma de seguir las operaciones globales de las firmas es a través de sus filiales extranjeras. Las 100 firmas más importantes de servicios globales tienen filiales en 315 ciudades en el mundo entero. Para el conjunto de las firmas multinacionales, el dato se eleva a 1 millón de filiales en el extranjero. 
El mapa global se intensifica cuando se examinan las redes financieras - por ejemplo, cuando lo que se comercializa no es la mantequilla ni el café sino que instrumentos financieros basados en esos commodities-. El mapa de commodities a futuro nos muestra que la mayor parte del comercio financiero ocurre en 20 bolsas de mercados futuros. Estas incluyen a los sospechosos usuales, Nueva York y Londres, pero a lo mejor no en sus roles familiares. De esta forma, Londres, no necesariamente famosa por su minería, es el mayor mercado de futuros en el palladium de metales. Pero adicionalmente a estos dos centros financieros principales, los 20 también incluyen a Tokio como el mercado más grande de platino, Sao Paulo, como uno de los mayores mercados en café y oro, el caso ya mencionado de Buenos Aires, como el principal mercado de semillas de girasol y a Shangai en cobre. Finalmente, algunos de estos centros son altamente especializados en formas inesperadas: Londres controla los mercados futuros de papas.

El mapa se reduce aún más cuando los 73 commodities transados de esta forma se agregan en tres grupos principales. Los cinco mercados globales de futuros (NYSE, LME, CBOT, TCOM e IPE), se localizan en Nueva York, Londres, Chicago y Tokio y concentran el $76 \%$ de las transacciones de estos 73 commodities a futuro comercializados globalmente. Agregados en tres grupos principales, un único mercado domina claramente en cada uno. Para el mercado de futuros de la agricultura, el CBOT (Chicago) controla la mayoría del comercio global, para energía es el NYSE (Nueva York), y para metales es el LME (Londres).

Este incremento en la capacidad de control apunta a los múltiples espacios económicos que están siendo generados. Así, los propios commodities provienen de más de 80 países y son vendidos en todos los países del mundo, aun cuando sólo cerca de 20 bolsas financieras controlan el comercio de mercados de commodities a futuro. Este estrecho mapa de comercio de commodities a futuro nos empieza a mostrar algo acerca del rol de las ciudades en la actual economía globalizada y crecientemente electrónica.
Es aquí cuando las ciudades globales entran en escena. Ellas no son lugares donde se producen commodities pero son los lugares donde se inventan los mercados de commodities a futuro de manera de facilitar el comercio global de estos commodities y parcialmente de gestionar los riesgos asociados, y son los lugares donde son comercializados estos futuros. Traen a un primer plano la distinción entre los sitios y las redes de producción de los bienes y los sitios y redes de gestión y coordinación del comercio de bienes y los instrumentos financieros de apoyo. Asimismo, vuelven concreta la que aparece como una de las tendencias contra intuitivas principales de la actual economía global: que mientras más globalizada y no material sea una actividad (el comercio de instrumentos financieros), más concentrado es el mapa global de esas actividades.

Existen otros tipos de mapas globales, más allá de los commodites, commodities a futuro y finanzas en general. Al concentrarnos en las redes globales de firmas de servicios globales y patrones de vuelo, aparece un mapa global mucho más distribuido.

\section{Firmas de servicios globales: fortaleciendo las geografías inter-ciudades}

El mapeo de las operaciones globales de las firmas de servicios especializados muestra casi lo opuesto de la aguda concentración de los mercados financieros a futuro mencionados anteriormente. Las operaciones de servicios de estas firmas están siendo demandadas en todas partes. Cuando los países se abren a firmas e inversionistas extranjeros y permiten que sus mercados se integren en los mercados globales, a menudo son las firmas de servicios extranjeros las que toman la provisión de servicios más especializados. Esto ha pasado en ciudades tan diversas como Buenos Aires y Beijing. Claramente, esto representa un mapeo particular de interconexiones entre un grupo de ciudades muy diversas. El análisis siguiente se concentra en las conexiones inter-ciudades entre 24 ciudades de las 315 ciudades del set de datos originales generado por Peter Taylor y sus colegas (2004; ver en general el sitio Web del GaWC) quienes generosamente han puesto los datos en el dominio público (ver Tabla 1). Lo que capturan los números es el grado en el cual estas 24 ciudades están conectadas 
a través de redes de oficinas de estas 100 firmas. Esta información es un microcosmos de un patrón que se repite a si mismo, una y otra vez, con una variedad de otros tipos de transacción, tales como la casi insignificante medida de una ciudad con locales de McDonald, o la extrema concentración de mercados de commodities a futuro discutida con anterioridad. Sobre este trasfondo, las medidas de conectividad de tales redes de oficinas constituyen un terreno intermedio, como parte importante de la infraestructura para las nuevas geografías inter-ciudades.

Excepto para Turín y Lagos, las 24 ciudades están en el tercio superior de las 315 ciudades donde estas firmas tienen ya sea sus sedes centrales o sus filiales. La Tabla 1 muestra la conectividad en conjunto de estas ciudades entre sí para seis grandes servicios corporativos. Cinco de nuestras ciudades están entre las 10 principales del total mundial de 315 donde estas firmas tienen operaciones. Londres y Nueva York aparecen en nuestra muestra, como lo hacen en general en el mundo, con niveles de conectividad mucho mayores que cualquier otra ciudad. Un segundo, y más diverso, grupo de nuestras 24 ciudades incluye a Tokio, Milán, Los Ángeles, y Sao Paulo. Un tercer grupo incluye a Ciudad de México, Yakarta, Buenos Aires, Mumbai, Shangai y Seúl. El cuarto agrupa a Moscú, Johannesburgo, Estambul, Manila y Barcelona. En un quinto grupo aparecen Caracas, Bogotá, Berlín, Dubai y El Cairo. Turín y Lagos se encuentran en un nivel considerablemente bajo de conectividad. Turín, con la menor conectividad de las ciudades, aloja sin embargo a oficinas de $14 \mathrm{de}$ estas firmas globales, lo que indica el grado en el

Tabla 1. Ciudades seleccionadas: ranking y conectividad global relativa entre 24 ciudades (todos los sectores)*

\begin{tabular}{|c|c|c|c|c|}
\hline Ranking & $\begin{array}{l}\text { Todos los sectores } \\
\text { de servicios }\end{array}$ & $\begin{array}{l}\text { Conectividad } \\
\text { bruta }\end{array}$ & $\begin{array}{l}\text { Conectividad } \\
\text { proporcional }\end{array}$ & $\begin{array}{c}\text { Conectividad } \\
\text { global relativa }\end{array}$ \\
\hline 1 & Londres $(\mathrm{LON})^{* *}$ & 11,789 & 0.0874 & 1.000 \\
\hline 2 & New York (NEW) & 11,524 & 0.0855 & 0.978 \\
\hline 3 & Tokyo (TOK) & 8,533 & 0.0633 & 0.724 \\
\hline 4 & Milán (MIL) & 7,178 & 0.0532 & 0.609 \\
\hline 5 & Los Ángeles (LA) & 7,068 & 0.0524 & 0.600 \\
\hline 6 & Sao Paulo (SAO) & 6,561 & 0.0487 & 0.557 \\
\hline 7 & Ciudad de México (MEX) & 5,824 & 0.0432 & 0.494 \\
\hline 8 & Jakarta (JAK) & 5,782 & 0.0429 & 0.490 \\
\hline 9 & Buenos Aires (BUE) & 5,779 & 0.0429 & 0.490 \\
\hline 10 & Mumbai (MUM) & 5,579 & 0.0414 & 0.473 \\
\hline 11 & Shanghai (SHA) & 5,293 & 0.0393 & 0.449 \\
\hline 12 & Seúl (SEO) & 5,210 & 0.0386 & 0.442 \\
\hline 13 & Moscú (MOS) & 5,079 & 0.0377 & 0.431 \\
\hline 14 & Johannesburgo (JOH) & 5,026 & 0.0373 & 0.426 \\
\hline 15 & Estambul (IST) & 5,004 & 0.0371 & 0.424 \\
\hline 16 & Manila (MAN) & 4,847 & 0.0359 & 0.411 \\
\hline 17 & Barcelona (BAR) & 4,770 & 0.0354 & 0.405 \\
\hline 18 & Caracas (CAR) & 4,317 & 0.0320 & 0.366 \\
\hline 19 & Bogotá (BOG) & 4,182 & 0.0310 & 0.355 \\
\hline 20 & Berlín (BER) & 4,117 & 0.0305 & 0.349 \\
\hline 21 & Dubai (DUB) & 4,033 & 0.0299 & 0.342 \\
\hline 22 & Cairo (CAI) & 4,011 & 0.0297 & 0.340 \\
\hline 23 & Lagos (LAG) & 1,997 & 0.0148 & 0.169 \\
\hline 24 & Turín (TUR) & 1,343 & 0.0100 & 0.114 \\
\hline
\end{tabular}

*Sectores: seis sectores de servicios corporativos especializados: banca/finanzas, consultorías de gestión, publicidad, legales, contabilidad y seguros. Se usa la metodología de Taylor pero aplicada a una muestra de 24 ciudades; se mide la conectividad entre estas 24 ciudades.

** Londres $=1,0$ 
cual estas firmas "conectan en red" el mundo, no obstante en términos especializados y parciales.

Alguno de estos resultados reflejan patrones claves en la reinvención de las economías espaciales. Así, Berlín y Turín aparecen en la parte baja del ranking debido a que los principales centros internacionales de negocios y finanzas en sus respectivos países, Frankfurt y Milán, son extremadamente poderosos en la red global y concentran una creciente proporción de cualquier componente global en sus economías nacionales. Este es un patrón recurrente en todos los países. En bancos y finanzas, la conectividad de Yakarta es elevada debido a que es un centro bancario principal y antiguamente establecido para el mundo musulmán en la región geopolítica de Indonesia, y por tanto de gran interés para las firmas occidentales pero también necesario para que estas firmas actúen como puente hacia Occidente. La conectividad de Shangai es alta debido a que es uno de los principales centros financieros de la región, y se ha convertido en el principal mercado nacional de valores en China - con Hong Kong volviendo a su posición como el centro financiero internacional líder-. Corea del Sur es la décima mayor economía en el mundo y ha experimentado una desregulación significativa después de la crisis financiera asiática de 1997. Ha convertido a Seúl como un sitio atractivo para las firmas financieras occidentales a medida que inversionistas extranjeros han estado comprando un conjunto de acciones tanto en Corea del Sur como en Tailandia desde la crisis financiera de 1997.

Dubai es un caso interesante que apunta a la construcción de una región completamente nueva, una no centrada en el mapa operacional de nuestras 100 firmas de servicios globales principales. Sólo en los últimos años Dubai se ha convertido en un centro financiero y de negocios importante en el corazón de una nueva región emergente que se extiende desde el Medio Oriente al océano Indico; su conectividad financiera global no se deriva principalmente de firmas financieras occidentales sino que crecientemente de firmas propias y regionales. Su conectividad financiera específica no se recoge cuando nos concentramos sobre las interacciones entre ciudades, pero su conectividad contable es extremadamente alta por la simple razón de que el estilo contable occidental rige al mundo.

Cuando estas medidas de conectividad global se desagregan por sectores especializados, se produce un cambio considerable debido al elevado nivel de especialización que marca a la economía global. En contabilidad, la Ciudad de México y, probablemente de manera más dramática, Dubai y El Cairo se mueven hacia los lugares más altos. Ellos están siendo profundamente conectados con los circuitos de la economía global, ellos median entre la gran economía global y sus regiones y por tanto ofrecen firmas contables del nivel superior llenas de negocios. En contraste, Shangai se mueve agudamente hacia abajo -las firmas globales contables han establecido sus operaciones en Beijing debido a que vincularse al gobierno chino aún resulta crítico.

Los otros sectores muestran cambios similares. Los a menudo agudos cambios en el grado de conectividad de los diferentes sectores en una ciudad dada se deben generalmente a desalineamientos entre los estándares globales para los servicios legales y contables y las especificidades de los sistemas nacionales. Las firmas globales de seguros han decidido claramente que localizarse en Johannesburgo y Shangai tiene sentido, a medida que suben a las primeras diez de nuestras ciudades. Esto indica que el sector doméstico de seguros o no está suficientemente desarrollado o es poco occidental para satisfacer a firmas e inversores, y por tanto las firmas extranjeras de seguros puede afianzarse. La baja conectividad de Seúl y Mumbai nos dice que el sector doméstico de seguros se está haciendo cargo de los negocios. La elevada conectividad de los servicios legales en el caso de Moscú, Sao Paulo y Shangai, todas las cuales se mueven hacia las 10 principales, señala la necesidad del estilo occidental de servicios legales en un contexto de crecientes números de inversionistas y firmas extranjeras. Sao Paulo, por ejemplo, aloja cerca de 70 firmas de servicios financieros sólo de Japón.

En gestión y consultoría, Buenos Aires, Sao Paulo, Seúl y Yakarta se mueven hacia las 10 principales en nuestra muestra, en buena parte debido a la dinámica apertura de sus economías nacionales 
en los 90, y a las oportunidades resultantes para los inversionistas y firmas nacionales y extranjeras. Barcelona, Mumbai y El Cairo han caído mucho más allá de nuestras 100 firmas globales de servicios, ya sea debido a que el sector doméstico puede proveer los servicios, como en el caso de Mumbai y El Cairo, o a oportunidades que yacen en otra parte, como lo sugieren las enormes inversiones a través de América Latina, y ahora incluyendo incluso bancos en el Reino Unido.

Para las primeras 100 firmas globales de publicidad, Mumbai y Buenos Aires, ambas con ricos sectores e industrias culturales, eran una atracción fuerte. Nuevamente, la débil presencia de firmas globales de publicidad en El Cairo y Dubai se debe a una orientación más aguda de estas ciudades a su región emergente.

Londres tiene la presencia más fuerte de estas firmas globales en contabilidad, banca/finanzas, seguros y Nueva York es más fuerte en publicidad y consultorías de gestión. Debe ser notado que este dominio se debe mayoritariamente a la aguda concentración de sedes centrales, así como filiales.

El mapa global producido por las operaciones de las 100 mayores firmas de servicios es dramáticamente diferente de aquel producido por el comercio financiero de mercados de commodities a futuro, el cual a su vez es diferente de aquel basado solamente en el comercio de estos commodities. La concentración extrema evidente en las finanzas lo sería más si se dibujara un mapa del comercio de bienes y los innumerables circuitos cruzados que conectan puntos de origen y destino. Esto sugiere que los servicios especializados son sectores que buscan ciudades, mientras más mejor.

\section{Medio ambiente construido homogeneizado: obscureciendo las diferencias económicas}

El homogeneizado y convergente estado del arte del paisaje urbano y crecientemente regional funciona en realidad como una "infraestructura". Como una infraestructura, estos medio ambientes construidos homogeneizados garantizan la provisión de todos los sistemas avanzados y necesidades o deseos lujosos por parte de las firmas y hogares en sectores económicos líderes. Distritos de oficinas, vivienda de lujo y distritos comerciales, conectividad convencional y digital, distritos culturales, sistemas de seguridad, aeropuertos y así sucesivamente, están todos incluidos y todos ellos son estado del arte.

Los análisis comparativos descansan en similaridades y diferencias para destacar sus ideas. La urbanización contemporánea, ya sea a escala urbana, metropolitana o regional, a menudo se ve como caracterizada por una homogeneización del paisaje urbano y un creciente conjunto de sus medio ambientes construidos. Esto es especialmente así en el caso de las ciudades globales y las ciudadesregiones globales debido a la intensidad y rapidez de la reconstrucción urbana en tales áreas. Y sin embargo, esto obscurece el hecho de la diversidad de las trayectorias económicas a través de las cuales las ciudades y regiones emergen y se desarrollan (como se discutió en la sección precedente), aun cuando el resultado visual final pueda parecer similar. Aparte de este análisis superficial basado en paisajes homogeneizados y medio ambientes construidos, surge una segunda posibilidad de inferencia espuria, que esta homogenización es una función de la convergencia económica, por ejemplo la noción de que hay un movimiento general hacia (una misma) economía del conocimiento. Ambas proposiciones -que paisajes visuales similares son indicadores tanto de una dinámica económica similar como de una convergencia- pueden en realidad capturar varia situaciones. Pero estas proposiciones también obscurecen condiciones clave que apuntan a la divergencia y a diferencias especializadas; de hecho, la divergencia y las diferencias especializadas se vuelven invisibles en tales nociones. Esas inferencias espurias necesitan ser tomadas en cuenta al intentar entender el carácter de esas mega-regiones.

Al nivel más general es posible empezar con desarrollos al nivel macro-económico, lo cual puede conducir fácilmente a los observadores a comprar la tesis de la homogeneización. Una tendencia estructural evidente en todas las economías que funcionan razonablemente es la creciente intensidad de los servicios en la organización de casi todos los sectores económicos, incluyendo sectores más bien rutinarios y a menudo no globalizados. Ya sea en la minería y la agricultura, o en sectores de 
servicios, tales como transporte y salud, más firmas están comprando más servicios al productor. Algo de esto se traduce en una demanda creciente de productores de servicios en las ciudades globales, pero mucho de esto se traduce en una demanda para tales servicios desde centros regionales, aunque a menudo son versiones menos complejas y avanzadas de esos servicios.

El crecimiento en la demanda de servicios al productor es entonces, en el análisis, una característica estructural de las economías de mercado avanzadas, que afecta a la mayoría de los sectores económicos. No es solamente una característica de los sectores globalizados ${ }^{20}$. Lo que la globalización agrega a esta tendencia es un agudo incremento en la demanda por complejidad y diversidad de conocimiento profesional ${ }^{21}$. Es esta diferencia cualitativa lo que conduce a un aumento de las economías de aglomeración mostradas por firmas en ciudades globales comparadas con otros tipos de áreas urbanas. Pero la tendencia estructural básica está presente en ambos tipos de áreas. Esta perspectiva también clarifica lo que desde mi perspectiva es de alguna forma una interpretación errónea sobre las tasas de crecimiento más altas de los servicios al productor en ciudades que no son globales. La tendencia es asumir ipso facto que

20 Para un aspecto particular -prácticas artísticas que alimentan al diseño comercial— ver Lloyd (2005).

21 Al desarrollar el modelo de ciudad global yo planteo que un indicador crítico es la presencia de servicios al productor especializados en red capaz de manejar las operaciones globales de firmas y mercados ya sean nacionales o extranjeros. Dadas las dificultades de medición, una forma aproximada de mirar a este sector en red es la incidencia y la combinación de servicios al productor en una ciudad. Esto frecuentemente se reduce a la participación del empleo en los servicios al productor como indicador del estatus de ciudad global. Esto está bien, aunque necesita una especificación empírica en lo referido a la calidad y combinación de las industrias de servicios al productor. Más problemático es interpretar una proporción pequeña, o una participación decreciente, o una tasa de crecimiento en declive, o una tasa de crecimiento más baja que en las ciudades no globales, como indicador de la situación de declive de una ciudad global o como señal de que la ciudad en cuestión no es una ciudad global. Similarmente problemática es la variante de este indicador, basada en el porcentaje que tiene una ciudad en el empleo nacional de servicios al productor, ya sea creciendo o disminuyendo; la noción sería que si una ciudad como Nueva York o Londres pierde participación en el empleo nacional de servicios al productor pierde poder. estas mayores tasas de crecimiento de los servicios al productor reflejan un declive y/o una salida de ellos de las ciudades globales. Estas mayores tasas de crecimiento son en realidad en buena medida un resultado del crecimiento rezagado de estos servicios en toda la economía nacional; las ciudades globales tuvieron sus tasas de crecimiento extremadamente altas mucho antes, en los ' $80^{22}$. Las tasas de crecimiento más bajas evidentes en las ciudades globales comparadas con otras ciudades no deberían ser entonces interpretadas como pérdidas de las primeras, sino más bien como resultantes del ingreso de estas últimas en esta nueva fase estructural de las economías de mercado $^{23}$. Mirar el problema de esta forma recodifica algunas interpretaciones comunes sobre el crecimiento y el declive.

Lo que resulta crítico para el análisis de esta sección es que el crecimiento de esta economía intermedia a lo largo de diversas áreas urbanas se debe a un tipo de convergencia estructural que explica la homogeneización del medio ambiente construido y los patrones espaciales, aun cuando los sectores de servicios sean radicalmente diferentes. Sin importar sectores económicos o localizaciones geográficas, las firmas están comprando más de estos servicios. Una firma minera, de transporte o de software, necesita comprar servicios legales y contables. En algún grado estos servicios pueden ser producidos en la misma ciudad y en un medio ambiente construido similar, aun cuando ellos están alimentando a sectores económicos y sitios geográficos muy diferentes del conjunto de la economía, incluyendo a la economía mega-regional. De esta forma los sectores de la "vieja economía" tales como la industria manufacturera y la

\footnotetext{
22 Para esa fase temprana, ver, por ejemplo, Drenan
} (1992)

23 Así, la alta tasa de crecimiento de los servicios al productor en ciudades pequeñas comparadas con las ciudades globales no es necesariamente una función de relocalización desde las ciudades globales a localizaciones con mejores precios. Es una función de la demanda creciente de firmas en todos los sectores por servicios al productor. Cuando estos servicios son para firmas y mercados globales su complejidad es tal que las ciudades globales son los mejores sitios de producción. Pero cuando la demanda es por servicios al productor rutinarios, ciudades a distintos niveles del sistema urbano pueden ser sitios de producción adecuados. La actual organización espacial de los servicios al productor refleja esta demanda dispersa entre los sectores económicos. 
minería también están fortaleciendo el crecimiento de la economía intermedia.

Esta convergencia estructural se filtra y homogeiniza a través de la organización espacial y el orden visual del medio ambiente construido. Da cuenta de patrones clave evidentes en ciudades pequeñas y grandes, como el notablemente bien documentado crecimiento de un nuevo tipo de clase profesional de jóvenes urbanitas y la gentrificación de altos ingresos y el crecimiento del sector cultural asociados. Esta convergencia y homogeneización del orden visual obscurece fácilmente las trayectorias y contenidos específicos a través de los cuales una región desarrolla la economía del conocimiento, como se discutió en la sección precedente de este artículo.

Visto de este modo, es posible empezar a calificar la tesis de la homogeneización y la convergencia. Hay un tipo de convergencia a un nivel sistémico abstracto, y al nivel del medio ambiente construido necesario para la nueva economía intermedia y los nuevos tipos de fuerza de trabajo profesional. Pero en la interfaz concreta y material de la economía y sus medio ambientes construidos, el contenido actual de los servicios especializados que habitan esos medio ambientes construidos puede variar agudamente.

De aquí, entonces, mi proposición de que los componentes críticos del paisaje urbano y regional homogeinizado/convergente, frecuentemente presentados como la quintaesencia de los nuevos medio ambientes construidos avanzados, son en realidad más semejantes a una infraestructura para los sectores económicos. Esto perturba al concepto (y la realidad) del medio ambiente construido tal y como es usado generalmente. La pregunta crítica entonces es qué es lo que habita esa "infraestructura". Aunque parezca similar no necesariamente implica un contenido, circuitos, o momentos de un proceso, similar. Esto ilustra la tesis de que dinámicas diferentes pueden ocurrir a través de formas espaciales e institucionales similares, y viceversa ${ }^{24}$. Así, el carácter sustantivo de

24 En Sassen (2006a), se plantea un argumento paralelo para el Estado liberal que está sujeto a las fuerzas de la globalización económica y política. El resultado no necesariamente significa que estos Estados pierden su distintividad, la convergencia en el modelo de la ciudad global, por ejemplo, no es el paisaje visual per se sino que su función como una infraestructura; y es, por encima de todo, el desarrollo e importación parcial de un conjunto de funciones especializadas y los efectos directos e indirectos que esto puede tener en la gran ciudad, incluyendo su medio ambiente construido.

Una pregunta que surge aquí es si esta distinción entre medio ambientes construidos homogeneizados, y el a menudo altamente diverso contenido que ellos alojan, también requieren ser parte de nuestro entendimiento de lo que es específico de una ciudad, una región urbana, o una megaregión ${ }^{25}$. Los edificios de oficina, trenes rápidos o aeropuertos de último modelo pueden parecer muy similares aunque pueden servir a sectores económicos muy diferentes. Estos tipos de diferencia se están volviendo crecientemente importantes para entender el lugar de una ciudad, una región y posiblemente una mega-región en la economía global. Hay dos razones para esto. Una es el giro desde una economía espacial keynesiana, que se esforzaba por lograr la convergencia territorial nacional, a una economía espacial post-keynesiana orientada hacia la focalización territorial (ciudades globales, silicon valleys, parques científicos, y así sucesivamente). La segunda es que la ventaja de una ciudad, región, y posiblemente de una megaregión, en la economía global es una función del posicionamiento en circuitos múltiples, altamente particularizados, y a menudo muy especializados. No es muy útil por tanto pensar en "el" lugar de "la" mega-región en "la" economía global.

\section{Conclusión}

Más allá de las sugerencias familiares de políticas, estos comentarios apuntan a implicancias de políticas que van más allá de asegurar que los sectores más dinámicos del desarrollo económico sean

sino que más bien ellos implementan las estructuras de gobernanza necesarias para acomodar proyectos globales y ellos lo hacen a través de la especificidad de la organización del Estado.

25 Para un examen detallado de esta combinación de temas visuales, de ingeniería urbana, arquitectónicos y económicos entre 16 grandes ciudades del mundo, ver Burdett (2006) y Sudjic (1993; 2005). 
considerados para su apoyo. También necesitamos enfrentar la excesiva focalización para asegurar más convergencia territorial. Los países desarrollados han entrado en una fase distinta de organización territorial, lejos de la convergencia Keynesiana y hacia una mayor focalización territorial de ciudades globales, silicon valleys y tecno polos. Mucha de esta focalización territorial está vinculada al desarrollo de las economías del conocimiento. Esto hace surgir varias preguntas sobre el contenido actual de estas economías del conocimiento y las relaciones entre esos contenidos y las viejas historias económicas de un lugar.

En segundo lugar, las economías del conocimiento son solamente un (aunque crítico) componente de las economías nacionales, regionales y urbanas. Priorizar sólo los sectores avanzados es un error crítico, y se corre el riesgo de llegar a una "economía de plantación", sin importar cuán elegante sea el cultivo. Depender de un monocultivo no es una buena forma de proceder. Adicionalmente, los sectores más avanzados requieren de una vasta colección de tipos de firmas, trabajadores y productos y servicios que no son usualmente vistos como "avanzados". Una implicancia clave de política es que la economía del conocimiento no debería ser reificada como algo que existe por sí mismo. Está incrustada en múltiples otros sectores.

El punto débil de la economía del conocimiento es el vasto conjunto de empleos de bajos salarios y firmas de bajas ganancias y bajas tecnologías, y espacios económicos subutilizados que son parte de la economía del conocimiento, aun cuando raramente sean codificados como tales. Si dar cuenta de estas condiciones no deseables requiere políticas "blandas", está bien. Pero el objetivo debe ser mejorar aquellos empleos, firmas y espacios. Esta es una forma de contrarrestar las fuertes tendencias hacia la polarización insertas dentro de la economía del conocimiento. Los sectores de bajo crecimiento pueden también contener tales tendencias hacia inequidades crecientes (aunque en un rango mucho más estrecho) pero raramente contienen los recursos para incluso empezar a contrarrestar la polarización. Un objetivo de política debería ser evitar los resultados de los Estados Unidos, donde un tercio de los puestos de trabajo están bajo los estándares, y las incidencias de accidentes laborales y muertes es la más alta de todos los países desarrollados.

Finalmente, si la relación entre la antigua economía material (manufactura, minería, agricultura, etc.) y la actual economía del conocimiento es repensada, es posible ver que esto no es un conflicto como típicamente se piensa, sino que la anterior puede alimentar a la primera. Esta relación usualmente se pasa por alto o no se da cuenta de ella en análisis sobre la economía del conocimiento debido a que la última es nueva y por tanto se asume fácilmente que debe superar a las antiguas economías de un lugar.

Una implicancia clave para repensar esa relación es que una ciudad o región puede construir fortalezas en términos de sus "diferencias especializadas". Por ejemplo la economía del conocimiento de Chicago es fuerte debido a que su pasado agroindustrial fue fuerte. Leyes, contabilidad, finanzas etc., todas tuvieron que ser desarrolladas para dar cuenta de las necesidades de la gran industria y los agro-negocios. Esta forma de ver va en contra de la forma común de ver que Chicago tuvo que neutralizar y superar su pasado agro-industrial. ¡Por el contrario! Ese pasado le dio sus ventajas especializadas en la economía nacional y global. Así una ciudad o región necesita ser construida sobre las especificidades de su historia económica en orden a alcanzar una diferenciación especializada (altos niveles de complejidad) para desarrollar su economía del conocimiento. Esto también significa distinguir el formato de la economía del conocimiento de su contenido (aunque ambas son centros financieros líderes, la economía del conocimiento financiera de Nueva York está construida sobre el comercio y las finanzas, y la de Chicago sobre la agricultura y la manufactura). Es esencial desarrollar entendimientos más completos de los parámetros y condicionalidades de las economías del conocimiento y de las implicancias para el desarrollo urbano y regional.

\section{Referencias bibliográficas}

Burdett, R. (Ed.) (2006). Cities: people, society, architecture. New York: Rizzoli. 
Dieter, E. (2005). The new mobility of knowledge: digital information systems and global flagship networks. En R. Latham \& S. Sassen (Eds.), Digital formations: it and new architectures in the global realm (pp. 89-114). Princeton: Princeton University Press.

Drennan, M. P. (1992). Gateway cities: the metropolitan sources of U.S. producer service exports. Urban Studies 29, 2, 217-35.

Gereffi, G., Humphrey, J. \& Sturgeon, T. (2005). The governance of global value chains. Review of international political economy (special issue: aspects of globalization), 12, 1, 78-104.

García, D. L. (2002). The architecture of global networking technologies. En S. Sassen (Ed.) (2002), Global networks/linked cities (pp. 39-69). New York and London: Routledge \&Ernst.

Globalization and World Cities Study Group and Network (GAWC.) (1998). En http://www.lboro.ac.uk/departments/gy/research/gawc.html.

Goldfeld, S. (Ed.) (2007). The economic geography of megaregions. Princeton, NJ: Policy Research Institute for the Region (Woodrow Wilson School of Public and International Affairs, Princeton University) and Regional Plan Association

Hagedorn, J. (Ed.) (2004). Gangs in the global city: exploring alternatives to traditional criminology. Chicago: University of Illinois at Chicago.

Harvey, R. (2007). The sub-national constitution of global markets. En S. Sassen (Ed.), Deciphering the global: its spaces, scales and subjects. New York and London: Routledge.

Henderson, J. (2005). Governing growth and inequality: the continuing relevance of stra- tegic economic planning. En R. Appelbaum \& W. Robinson (Eds.), Towards a critical globalization studies (pp. 227-236). New York: Routledge.

Lloyd, R. (2005). Neobohemia: art and bohemia in the postindustrial city. London \& New York: Routledge.

Rutherford, J. (2004). A tale of two global cities: comparing the territorialities of telecommunications developments in Paris and London. Aldershot, UK \& Burlington, VT: Ashgate.

Sassen, S. (2001). The global city (2a Ed.) (2001). Princeton: Princeton University.

(2006a). Territory, authority, rights: from medieval to global assemblages. Princeton, NJ: Princeton University Press. (2006b). Cities in a world economy ( $3^{\mathrm{a}}$ Ed.). London: Sage PineForge.

Saxenian, A. (1996). Regional advantage: culture and competition in Silicon Valley and Route 128. Cambridge, MA: Harvard University Press.

Scott, A. J. (2001). Global city-regions. Oxford: Oxford University Press.

Sudjic, D. (1993). The hundred mile city. London: Harvest/HBJ.

(2005). The edifice complex: how the rich and powerful shape the world. U.S.A.: Penguin Press.

Taylor, P. (2004). World city network: a global urban analysis. New York: Routledge.

World Federation of Exchanges (2007). Annual statistics for 2006. Paris: World Federation of Exchanges. 